\title{
Deterioration Mechanisms in Dragline Wire Ropes
}

\author{
Daya Dayawansa, ${ }^{1,}$, Mahinda Kuruppu ${ }^{2, b}$ and Fidelis Mashiri ${ }^{3, c}$ \\ ${ }^{1}$ Maintenance Technology Institute, Department of Mechanical Engineering, Monash University \\ (Caulfield Campus), P O Box 197, Caulfield East, VIC 3145, Australia \\ ${ }^{2}$ Western Australian School of Mines, Curtin University of Technology, Locked Bag 22, Kalgoorlie, \\ WA 6433, Australia \\ ${ }^{3}$ School of Engineering, University of Tasmania, Private Bag 65, Hobart, TAS 7001, Australia \\ åDaya.Dayawansa@eng.monash.edu.au, ${ }^{b}$ m.kuruppu@curtin.edu.au, \\ 'Fidelis.Mashiri@utas.edu.au
}

Keywords: Dragline, wire rope, maintenance, deterioration mechanisms.

\begin{abstract}
Failures in hoist and drag ropes are studied and described based on site inspections on Marion and BE draglines. Causes of the failures are discussed. Some of the analyses of the wire rope failures centres on the wire rope accessories through which these ropes travel during machine operation. The influence of wire quality on wire rope life is also studied. Visual and metallographic examinations are both used in this study leading to a better understanding of deterioration mechanisms that lead to failure of hoist and drag ropes under service loading.
\end{abstract}

\section{Introduction}

The operation of draglines in open cut mines hinges among other things, on the integrity of wire ropes. The integrity of ropes ensures that a safe operating environment is maintained under service. An understanding of the integrity of ropes also leads to better planning in terms of rope changes which can lead to favourable cost to production ratios. The breakage of a dragline hoist or drag rope during operation can have serious consequences. The potential energy carried in the ropes during operation can cause damage to wire rope accessories or surrounding structures because the ropes have a capacity to recoil at considerable speeds and can therefore cause damage through impact. The integrity of wire ropes is dependent on an understanding of rope deterioration mechanisms. The deterioration is affected by the cyclic nature of loading in wire ropes during the dig, swing and dump cycles which leads to fatigue failure of different dragline rope types.

Fatigue is the reversal or fluctuations of loading that lead to the initiation and growth of cracks. Most fatigue cracks occur in the outside wires, although they can also occur in any wire in the rope's cross section. There are three primary fatigue loading conditions which can occur in ropes (Chaplin, 1994): (a) Bending-over sheave fatigue, (b) Tension-tension fatigue and (c) Free bending fatigue. In the hoisting applications all of these are present to different degrees.

Deterioration of steel wire ropes occurs due to various conditions of usage and different damage mechanisms. Typical loadings experienced by individual wires in a rope are very complex and include a combination of tension, torsion, bending and shear. In dragline applications all these loads will be variable and hence lead to fatigue in the wire material. Other environmental conditions arising due to the above mentioned forces and interlocking of the wires can be inter-wire abrasive wear, external abrasive wear, corrosion and external damage. The severity of loading and environmental conditions can greatly influence rope life. For example, the environmental conditions that the drag ropes experience are quite severe resulting in short lives whereas those experienced by suspension ropes are moderate and they tend to last much longer.

The factor that determines the condition of a rope at a given point in service is the damage sustained by the rope and its remaining load carrying capacity. This damage resulting from various deterioration mechanisms finally manifests as broken wires and loss of load carrying capacity. At 
that stage the maintenance personnel have to make a judgment on the remaining life of the rope and the level of failure risk if the rope is to be in service until the next inspection.

\section{Failures in Hoist Ropes}

It has been shown that BE1370 hoist rope life is much better than that for M8050 draglines (Dayawansa et al 2005). According to the information obtained by inspecting a large number of BE1370 hoist ropes, the main reason for this is the uniform wear on the perimeter of the hoist ropes. Therefore, during the later stages of life the wire breaks are more evenly distributed over the length and perimeter of the rope. A typical BE1370 hoist rope and its wear patterns are shown in Figure 1.

The favourable features in BE1370 draglines that contribute to the uniform rope wear can be that:

(a) Hoist ropes remain straight from the boom point sheave to the drum, except at the deflection sheaves. The rope does not exert significant forces on deflection sheaves except for the self weight.

(b) The fleet angle on the drum is relatively small.

(c) When the load is applied onto the hoist rope, it tends to twist making the contact with sheaves uniform.

(d) The rope does not bend out of the planes of any of the sheaves. This also facilitates the rotation of the rope when loaded.

On the other hand the wear in Marion hoist ropes is non-uniform, and the wear is most severe in the portion of the rope that passes over the gantry sheave. A typical M8050 hoist rope and its wear patterns are shown in Figure 2. The short span between the drum and the gantry sheave also contributes to this as the rope does not get sufficient room to twist under load.

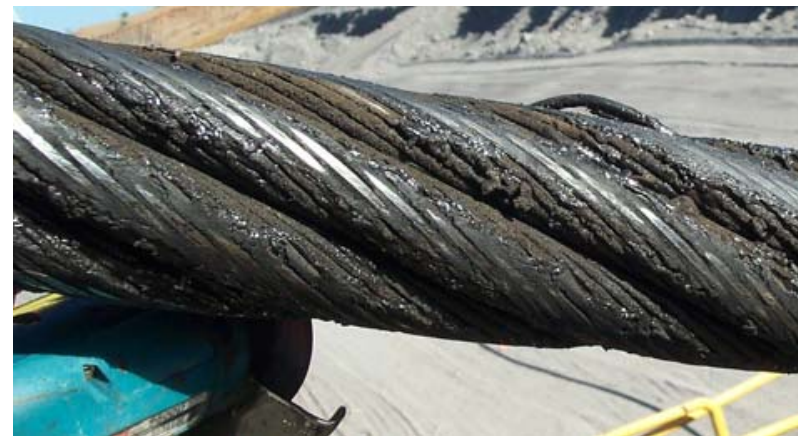

(a) Wear on One Side

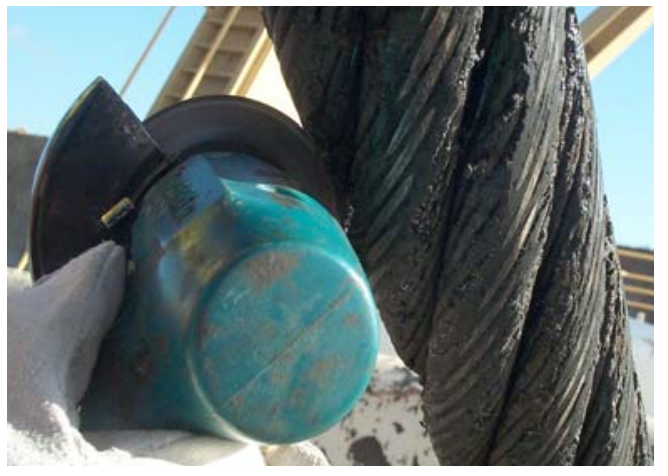

(b) Wear on the Other Side

Figure 1: Uniform Wear on a BE1370 Hoist Rope

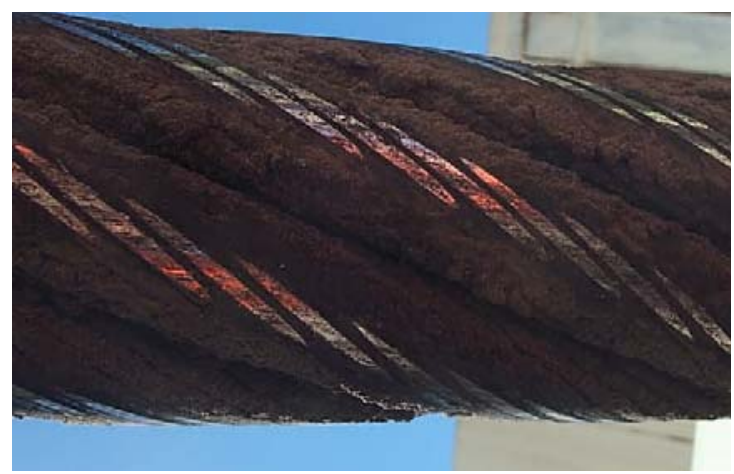

(a) Heavy Wear on One Side

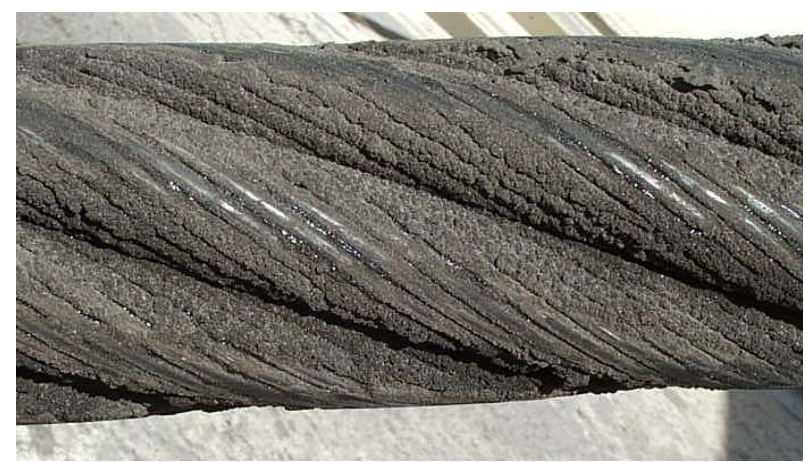

(b) Light or No Wear on the Other Side

Figure 2: Non-Uniform Wear on a M8050 Hoist Rope 
In one M8050 hoist rope, closer to the drum end, there was a length of $~ 10 \mathrm{~m}$ where a unusually large number of wires had been broken on one side of the rope as shown in Figure 3. This damage was likely to be due to the abrasive wear on the gantry sheave.

At the gantry sheave the hoist rope bends in two directions. In most normal situations, if a rope direction is to be changed, a sheave is placed in the plane of bending of the rope. However, at the gantry sheave this is not the case. At the gantry sheave, whether the rope is in the plane of the sheave depends on the number of turns in the drum. The number of turns in a drum results in a given fleet angle. Therefore, when the fleet angle is high the rope rubs on the side of the sheave groove, resulting in uneven wear. Furthermore, the friction between the sheave and the rope prevents the rope rotation when the load is applied. Given this situation, the lubrication of the rope at the gantry sheave is extremely important.

The non-uniform wear problem can be rectified by introducing an additional sheave in the second plane of bending.
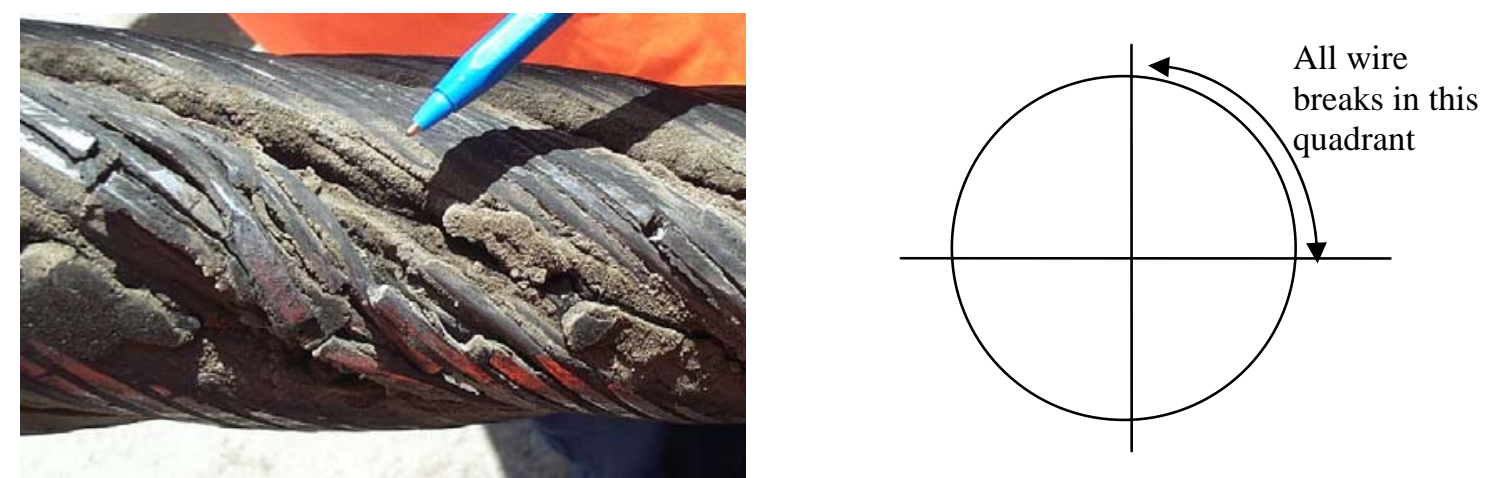

Figure 3: A Large Number of Wire Breaks Concentrated on One sector of M8050 Hoist Rope

\section{Failures in Drag Ropes}

The main failures in drag ropes are either due to abrasive wear or wire breaks at sockets. It has been observed that the wire breaks sometimes concentrate at fairlead locations at the time the bucket is picked up. The reason for this phenomenon is not known. The wire breaks at sockets are common to both Marion and BE draglines. Typical wire breaks at sockets is shown in Figure 4.

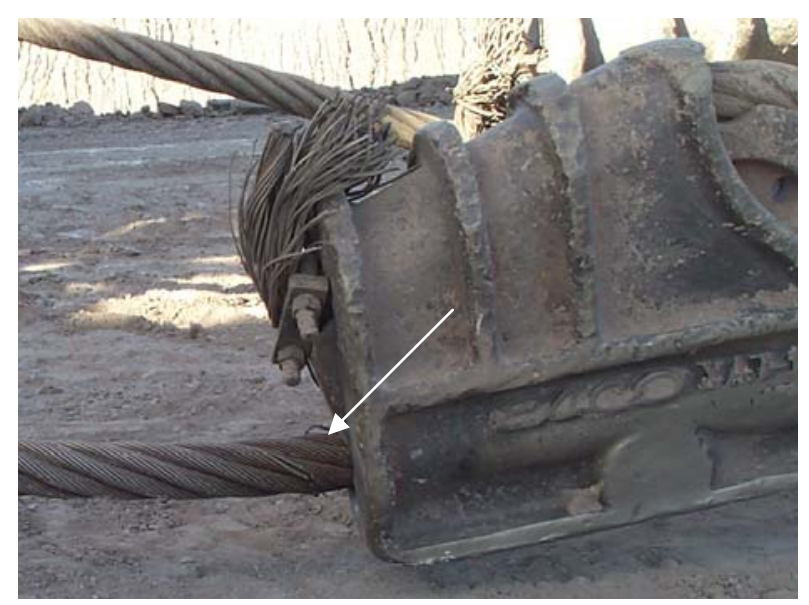

Figure 4: Typical Wire Breaks at Sockets

The drag ropes suffer from heat damage more often due to rope dragging over hard material and boulders. The surface of the outer wires gets heated up due to friction and then gets subjected to rapid cooling. As a result of this process the wire material can change phases and undesirable 
martensite can be formed on the worn out surfaces of the wires. The necessity of proper lubrication in relieving excessive friction cannot be over emphasized for both hoist and drag ropes.

\section{Microscopic Investigations of Failed Samples}

Dragline Hoist Ropes: A portion equal to the wire rope lay length was taken from a discarded M8050 hoist rope to undertake a detailed examination. The objectives of the study were to determine the number of wire breaks inside of the rope and also to examine the nature of the fatigue fractures in wires.

The rope showed typical non-uniform wear on the outer wires as pointed out previously. Figure 5 shows the state of the outer strands and the core of the rope after it was dismantled. The outer strands showed typical abrasive and plastic wear on the outer surface as shown in Figure 5(b), and indentations on the inner wires as seen from Figure 5(a). There were a large number of internal wire breaks on the outer strands as shown in Figure 5(a). Most interestingly, the core of the rope was literally broken into pieces as seen in Figure 5(c), making it a futile exercise to count the number of wire breaks. Based on the number of wires broken within one lay length this rope would have been well outside all known discard criteria, yet it continued to be in service.

During the field inspection, sections of broken steel wires were removed from the outer strands of several dragline hoist ropes and subjected to a detailed optical and metallographic examination. Broken wires taken from the core strand of another Marion dragline hoist rope were also examined.

Optical examination of the outer strand wires revealed a failure mode common to all of them; namely fatigue fracture originating at a heavily deformed surface as typically shown in Figure 6.

The fatigue fracture indicated by the arrow in Figure 6 has initiated at a severely abraded and crushed surface. Metallographic examination of longitudinal sections taken along the defective wires revealed the presence of a brittle martensitic layer (arrowed) associated with the heavily abraded surface as shown in Figure 7. Below the martensite is the heavily drawn microstructure of the wire material. This brittle martensite phase can give rise to cracking, which can propagate transversely into the parent microstructure and eventually lead to failure.

The core strand taken from a discarded Marion dragline hoist rope revealed its wires were severely crushed as shown in Figure 8(a). Closer examination of the wire failure surface revealed that the fracture was not associated with the deformed sharp regions as was the case in the outer strands. The initiation point of the fracture was in the relatively undeformed part of the wire as shown in Figure 8(b). It is not possible to conclude whether the fatigue crack initiated before the wire was crushed.

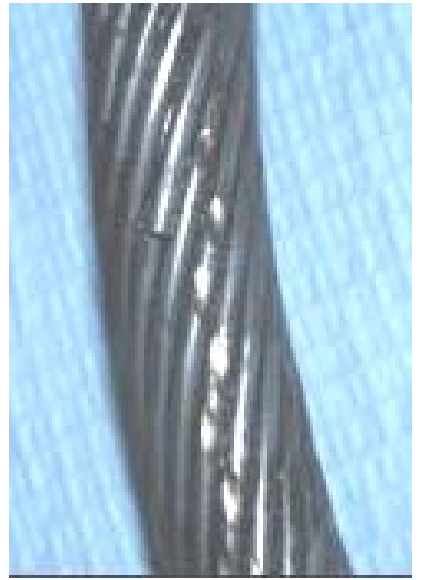

(a) Indented Wires Inside of Strand Figure 5: Discarded M8050 Hoist Rope

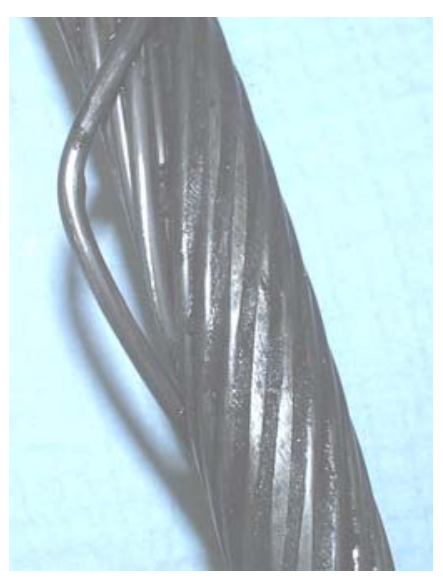

(b) Worn out Wires - (c) Core - Wires Broken into Small Pieces Outside of Strand
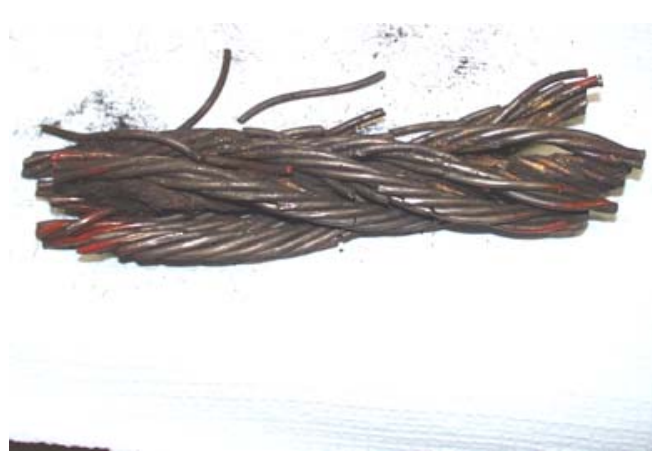


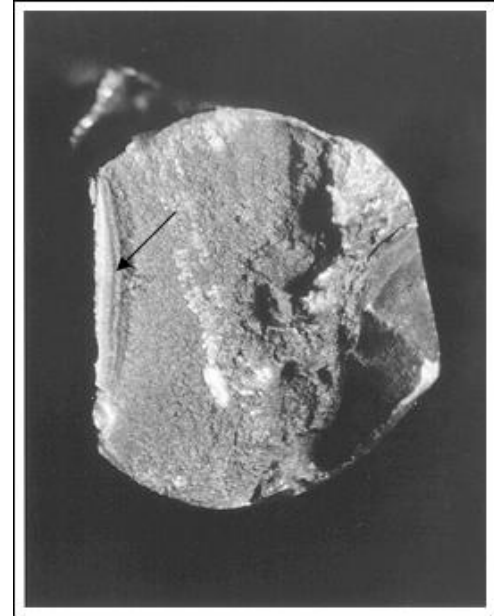

Figure 6: Typical Wire Break in Outer Strand of Hoist Rope

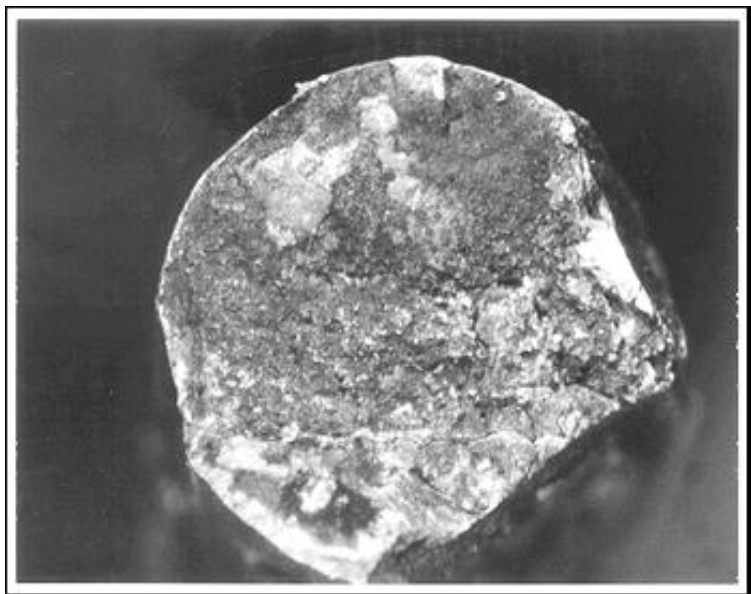

(a) Severely Crushed Core Strand Wire

Figure 8: Wire Failures from a M8050 Hoist Rope Core

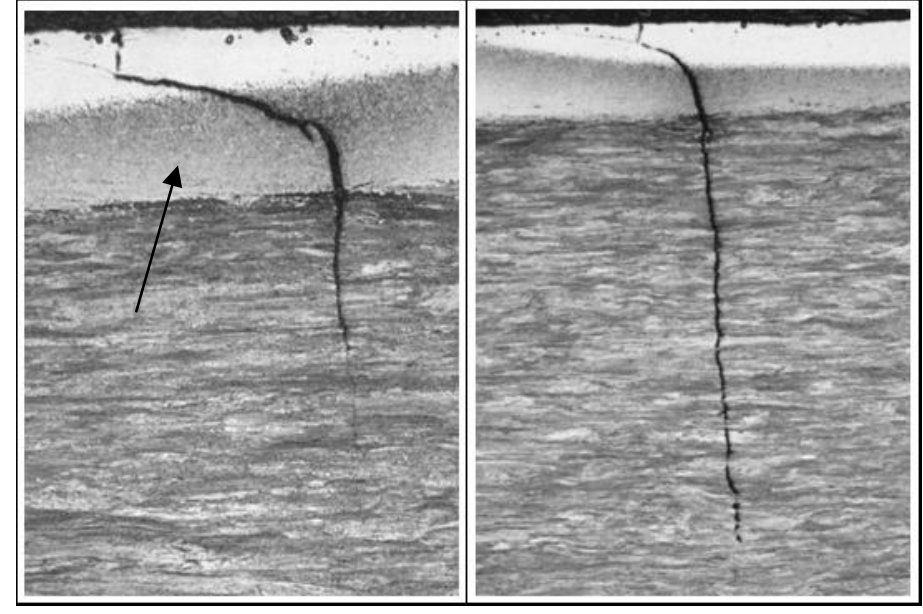

Figure 7: Martensite Layer and Heavily Drawn Microstructure

\section{Wire Quality and its Influence on Rope Life}

Material issues can also contribute to rope life reductions. This issue needs to be addressed by the manufacturers. It is not practical to regularly undertake full size rope tests because of the specialist equipment required for these tests. This equipment is only available in few laboratories around the world. However, it is possible to undertake representative wire tests for each batch of manufactured wire ropes. Results of these tests can be archived as records of the quality of the wires making up the wire ropes which are in turn used in different draglines.

It is also very important to understand what the implications of wire quality is on fatigue life of the rope. An investigation on a failed suspension rope revealed that the surface irregularities of the wires contributed to the premature failure of the rope. The samples of the tested wires from this rope are shown in Figure 9. It is believed that the surface irregularities were generated at the stage of wire production. If routine wire tests are conducted as part of the quality checks the quality and reliability of the ropes can be improved. 


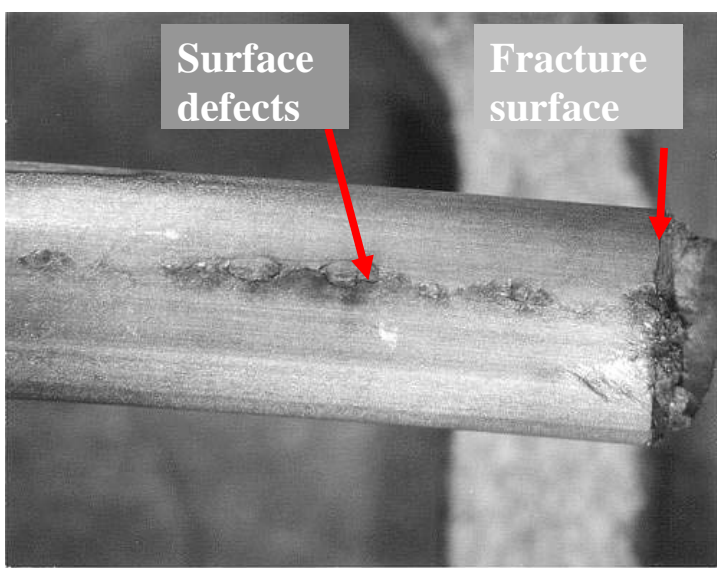

(a) Surface Defects Figure 9: Surface Defects on Subsequent Fatigue Failures

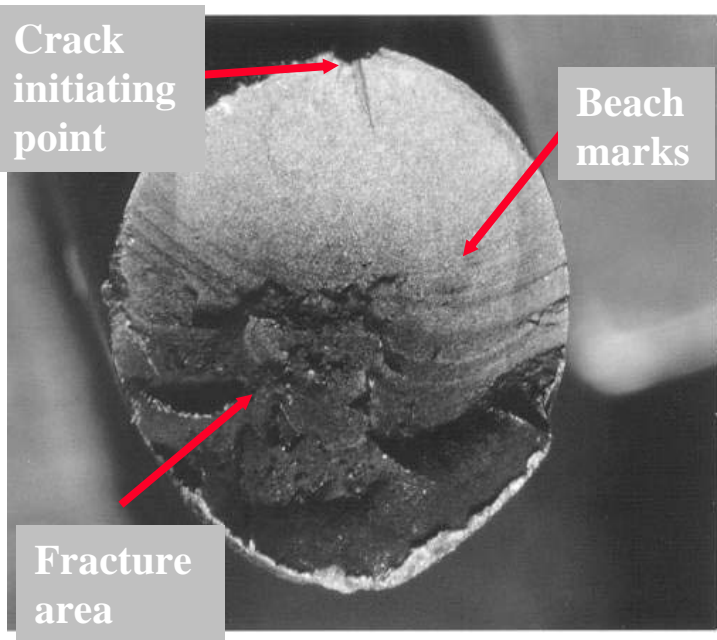

(b) Fatigue Failure due to Surface Defects a Suspension Rope Wire and

\section{Conclusions}

Failure in dragline wire ropes can occur due to the following deterioration mechanisms:

Abrasive and Plastic Wear: The wires on the outside surface of hoist and drag ropes are subjected to abrasive and plastic wear due to contact with sheaves and the drums. Abrasive wear is generally due to the rubbing of the rope on a hard surface such as a sheave. On the other hand, wire wear can take place under high compressive contact stresses causing the wires to plastically deform. In the process of plastic deformation the wire hardens and becomes brittle. As a result fatigue cracks are readily initiated in the plastically deformed area leading to failure of individual wires (Chaplin, 1994). In most situations the abrasive and plastic wear occurs simultaneously.

Heat Damage: The drag ropes suffer from heat damage more often due to rope dragging over hard material and boulders resulting in the formation of undesirable martensite.

Crushing of Wires: The wires of different strands contact each other at oblique angles inside each strand as well as on the rope core. The wires move relative to each other at these points under heavy contact pressures when the rope is bending over sheaves and drums. Combined crushing and plastic wear can take place significantly deforming the wire cross-sections.

Wire Quality related failure: Surface irregularities of the wires used in the manufacture of wire ropes can become crack initiation locations under fatigue loading during service.

\section{Acknowledgements}

The authors would like to thank the following sponsors, Australian Coal Association Research Program (ACARP), Monash University, BHP-Billiton Mitsubishi Alliance (BMA), OneSteel Wire Rope, and BE International.

\section{References}

[1] C.R. Chaplin, 1994. Hoisting ropes for drum winders - The mechanics of degradation, Mining Technology, pp. 213-219

[2] Dayawansa P., Mahinda K., Mashiri F.R. and Bartosiewicz H. 2005, "Wear of Dragline Ropes”, Moving Technology-Maintaining Competence, Proceedings of $6^{\text {th }}$ Australasian Coal Operators' Conference, COAL2005, Editor: Pat Hanna, Australian Institute of Mining and Metallurgy, 26-28 April 2005, Brisbane, Australia, pp. 153-160 